\title{
A dispersão da psicologia: do debate epistemológico ao estudo de uma divisão de psicologia aplicada
}

\author{
La dispersión de la psicología: del debate \\ epistemológico al estudio de una división de \\ psicología aplicada
}

\section{The dispersion of Psychology: from the epistemological debate to the study of a division of applied psychology}

Arthur Arruda Leal Ferreira ORCID ID: 0000-0002-2059-8877 Universidade Federal do Rio de Janeiro (UFRJ), Brasil

Bruno Figueiredo Foureaux ORCID ID: 0000-0001-9944-7053 Universidade Federal do Rio de Janeiro (UFRJ), Brasil

Natalia Barbosa Pereira ORCID ID: 0000-0003-3677-6962 Universidade Federal do Rio de Janeiro (UFRJ), Brasil

Rafael de Souza Lima ORCID ID: 0000-0002-1351-4970 Universidade Federal do Rio de Janeiro (UFRJ), Brasil

David de Lima Brito ORCID ID: 0000-0003-3084-6122 Universidade Federal do Rio de Janeiro (UFRJ), Brasil

Paulo Henrique Mendes da Cunha ORCID ID: 0000-0003-1490-4791 Universidade Federal do Rio de Janeiro (UFRJ), Brasil

Thaíssa Rosa Alves Almada ORCID ID: 0000-0001-8291-3513 Universidade Federal do Rio de Janeiro (UFRJ), Brasil 
Isabella Gomes Freire

ORCID ID: 0000-0001-6624-3863

Universidade Federal do Rio de Janeiro (UFRJ), Brasil

Marcus Vinícius do Amaral Gama Santos

ORCID ID: 0000-0002-6827-4580

Universidade Federal do Rio de Janeiro (UFRJ), Brasil

Autor referente: paulomea29@gmail.com

Historia editorial

Recibido: 28/02/2019

Aceptado: 13/09/2019

\section{RESUMO}

Este artigo trabalhará a discussão quanto a pluralidade ou unidade da psicologia. Destacaremos como este tema se projetou no cenário dos países francófonos ao longo do século passado. Como contraponto, investigaremos os modos de articulação produzidos pelos saberes e práticas psicológicos, através dos atuais Estudos em Ciência, Tecnologia e Sociedade, a partir da Teoria AtorRede e da Epistemologia Política. Examinaremos os modos de engajamento que certas técnicas terapêuticas produzem no intercurso com diversos atores humanos, mas igualmente com dispositivos sociotécnicos. Estas técnicas terapêuticas estão sendo acompanhadas na Divisão de Psicologia Aplicada da UFRJ desde 2010 por meio de: descrições dos artefatos presentes em certas práticas terapêuticas e dos dispositivos nela presentes; entrevistas com pessoas em entrada e intercurso de terapia, estagiários, orientadores e responsáveis pela triagem; e observações etnográficas em sessões de supervisão de abordagens diversas. Por meio dos resultados destas pesquisas, discutiremos as formas de conexão das práticas psi.

Palavras chave: Dispositivos clínicos; produção de subjetividade; teoria ator rede; epistemologia política

\section{RESUMEN}

Este artículo trabajará en la discusión sobre la pluralidad o unidad de la psicología. Vamos a destacar cómo este tema fue proyectado en el escenario de los países francófonos a lo largo del último siglo. Como contrapunto, investigaremos los modos de articulación producidos por los saberes y prácticas psicológicas, a través de los actuales Estudios en Ciencia, Tecnología y Sociedad, basados en la Teoría Actor-Red y en la Epistemología Política. Examinaremos los modos de compromiso que ciertas técnicas terapéuticas producen en el intercurso con varios actores humanos, 
pero también con dispositivos sociotécnicos. Estas técnicas terapéuticas vienen siendo acompañadas en la División de Psicología Aplicada de la UFRJ desde 2010 por medio de: descripciones de los artefactos presentes en determinadas prácticas terapéuticas y de los dispositivos presentes; entrevistas con personas en renta y pasantía de terapia, pasantes, consejeros y responsables de la selección; y observaciones etnográficas en sesiones de supervisión de diversos enfoques. A través de los resultados de estas investigaciones, discutiremos las formas de conectar prácticas psi.

Palabras clave: Dispositivos clínicos; producción de la subjetividad; teoría de la red de actores; epistemología y política

\section{ABSTRACT}

This paper will discuss the plurality or unity of psychology. We will highlight how this theme was projected in the francophone countries scenery over the past century. As counterpoint we will investigate the ways of articulation produced by psychological knowledges and practices through the recent Science, Technology and Society Studies, from Actor-Network Theory and from Political-Epistemology. We will examine the modalities of engagement that certain therapeutic techniques produce in the relation with diverse human actors and socio

\begin{abstract}
technical devices. These therapeutic techniques are being accompanied in UFRJ's Division of Applied Psychology since 2010 through: the description of the artifacts present in certain therapeutic practices and of the devices present in those; interviews with people entering and under therapy, trainees, mentors and the ones responsible for the screening; and ethnographic observations in supervision sessions of diverse approaches. Through the obtained results, we will discuss the ways of connection of psi practices.
\end{abstract}

Keywords: Clinical devices; production of subjectivity; actor network theory; political epistemology

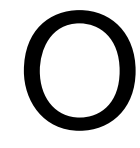
objetivo geral deste trabalho é retomar a discussão sobre a dispersão da psicologia, tão presente ao longo do século $X X$, deslocando a predominante análise epistemológica para uma descrição ao modo dos atuais Estudos em Ciência, Tecnologia e Sociedade (doravante CTS), notadamente por meio de conceitos propostos pela Teoria Ator-Rede (de Bruno Latour, John Law e Annemarie Mol) e pela Epistemologia Política (de Isabelle Stengers e VincianeDespret). Para tal, mais do que discutir as psicologias num sentido geral, tomaremos as práticas clínicas, e mais 
exatamente em um cenário onde diversas correntes podem se encontrar: a Divisão de Psicologia Aplicada de uma universidade. As Divisões ou Serviços de Psicologia Aplicada, em seus diferentes formatos, apresentam-se como um espaço onde o ensino da psicologia cruza com a formação de especialistas (como terapeutas), e com a oferta de serviços comunitários. No caso deste trabalho analisaremos a Divisão de Psicologia Aplicada (doravante DPA) da Universidade Federal do Rio de Janeiro (UFRJ) por duas formas: a) por entrevistas a supervisores, estagiários e usuários; b) pelo acompanhamento de grupos de supervisão de estágios clínicos específicos. A proposta é examinar os modos de conexão entre os representantes de diversas correntes ou bandeiras da psicologia, por meio de aspectos didáticos dos supervisores, pela formação dos estagiários-terapeutas e pela circulação de pacientes entre grupos de orientações diferentes. A partir da descrição destes aspectos, discutiremos os modos de conexão das práticas psi.

\section{Discussões epistemológicas em cenários francófonos}

Nos países de língua francesa, o debate sobre a pluralidade do saber psicológico tem sido conduzido desde a década de 1940, com os defensores da unidade como Daniel Lagache (1988/1949) se opondo aos denunciantes da sua pluralidade como Georges Canguilhem (1973), Foucault (1994/1957) e Bernard (1983). Os primeiros sustentam que a unidade está calcada ou num projeto de uma ciência das "respostas significativas nas quais o ser vivente integra as tensões que ameaçam a integridade e o equilíbrio do organismo" (Lagache, 1988/1949) ou na própria possibilidade de operacionalização empírica dos problemas (Pagés, 1958). Por outro lado, os autores que sustentam a pluralidade também se caracterizam por tentar explicá-la. É assim que Canguilhem e Gagey, inspirados no Racionalismo Aplicado de Gaston Bachelard, delegam a pluralidade a projetos diferenciados, inspirados em outras ciências, que habitariam o campo psicológico. 
Canguilhem (1973) aponta para cinco possíveis projetos psicológicos sem qualquer entrelaçamento entre si: a) como ciência da alma (de inspiração aristotélica); b) como ciência do sentido interno (equivocadamente embasado nas meditações cartesianas); c) como física do sentido externo (contrastando a nossa experiência com a realidade apontada pela física); d) como ciência do sentido íntimo (inspirada em questões psicopatológicas); e) como ciência das reações (apoiada na biologia, mas também no tecnicismo e no igualitarismo meritocrático das sociedades contemporâneas). Foucault, ainda que não fosse protagonista neste debate, apresenta em 1957 um texto sobre "A pesquisa científica e a psicologia" (1994/1957), em que discute os modos de pluralidade deste saber. Neste trabalho, que é um de seus primeiros textos, Foucault levanta uma série de tensionamentos entre a pesquisa positiva, a contradição das suas práticas e a negatividade que este autor supõe neste momento como atributo essencial ao humano. Contudo, a contradição mais notável no seio da psicologia destacada por Foucault estaria em seu estatuto como saber crítico, posto que estaria num regime entre a tomada de consciência de nossa constante produção de ilusões, própria da história, e a denúncia dos erros, inerente às ciências naturais. A psicologia teria, pois, um estatuto híbrido: crítica como a história, mas realista como a ciência. Contudo, esse saber não atingiria nem a positividade das ciências (a objetividade) nem a da história (o reconhecimento das ilusões), restando apenas a constante ultrapassagem crítica de si que a caracteriza (Foucault, 1994/1957, pp. 144-145). É desse modo que esse "jovem Foucault" explica a pluralidade da psicologia: ela ocorre porque cada orientação sua (behaviorismo, gestaltismo, psicologia dinâmica, etc.) se ergue nessa missão de uma denúncia dos mitos (subjetivismo, elementarismo, objetivismo) das demais, sempre as posicionando entre a ilusão e o erro.

Numa análise pormenorizada, Bernard (1983) aponta que esta pluralidade epistemológica não é suficiente para se compreender a dispersão psicológica. Para tal, seria necessário ter em conta um conjunto de psicotécnicas, ou de práticas sociais 
em que a psicologia estaria assentada (tese semelhante à de Foucault). Desta forma, podemos entender a diversidade do campo psicológico como o cruzamento diverso de projetos científicos oriundos de outros saberes com práticas sociais ou psicotécnicas. Mas o que sustentaria essa diversidade de orientações psicológicas, com fundamentos, atuações e resultados tão diversos (e mesmo contraditórios)? Bernard (1983) nos mostra que uma das principais marcas da psicologia é a produção de uma cultura psicológica, como efeito de suas práticas mais imediatas.

A partir destas considerações, propusemos especialmente a partir do trabalho de Bernard, um modelo simples para explicar a pluralidade do campo psicológico, designado "Máquina de Múltiplas Capturas". O funcionamento desta Máquina ocorreria em algumas fases. Em um primeiro momento pode-se dizer que todas as psicologias advêm de uma série de experiências sociais ou psicotécnicas (nas palavras de Bernard), como a busca de verdades via confissão, a tentativa de disciplina sobre as condutas individuais, o exame das nossas experiências pessoais visando preveni-las das ilusões, a tentativa de controle da loucura, ou ainda o isolamento e ortopedia da infância. Num segundo momento, estas práticas demandariam um lastro de verdades, buscando em métodos e conceitos das ciências naturais como a física, fisiologia, biologia e ciências informacionais. Deste cruzamento de conceitos e métodos científicos com práticas sociais surgiriam às diversas orientações psicológicas. É assim que no gestaltismo o exame da experiência ingênua culminaria no equilíbrio das formas, enquanto conceito compatível com a física dinâmica; no behaviorismo, a tentativa de disciplina das atividades humanas na educação e no trabalho, conduziria à força dos condicionamentos e às adaptações naturais do organismo biológico; na psicanálise, as práticas de confissão e o esforço de desvelar as fontes dos nossos desejos e de nossas mais íntimas verdades, nos levaria a uma visão do homem como um ser desejante, marcado pela impossibilidade de equilíbrio energético dentro do ciclo pulsional. 
Contudo, esta discussão epistemológica nos rende apenas condenações da pluralidade da psicologia ou sua classificação em orientações gerais assim como descrições gerais de seus modos de funcionamento. Seria necessário avançarmos na direção de instrumentos conceituais mais atuais, além de um campo de análise mais específico, para examinarmos de modo mais detido os modos de conexão das práticas psicológicas em ação. No que tange às ferramentas conceituais buscaremos nos Estudos CTS, notadamente os propostos pela Teoria Ator-Rede (de Bruno Latour, John Law e Anemarie Mol) e pela Epistemologia Política (de Isabelle Stengers e Vinciane Despret). E o cenário de nossas descrições será o campo das práticas clínico-terapêuticas, graças a um dispositivo que permite a conexão entre diferentes versões das abordagens terapêuticas. É nesta epistemologia encarnada, que pretendemos herdar esta questão da dispersão da psicologia, estudando-a em um dispositivo comunitário-terapêutico, mas que poderia ser trabalhada nos mais diversos cenários vinculados à psicologia, onde os graus de unidade podem se apresentar das mais diversas e surpreendentes formas.

\section{As práticas clínicas: controvérsias de delimitação}

Um enviesamento epistemológico atravessa igualmente a análise das práticas clínicas, que são temas de nosso trabalho de campo (Esta discussão pode ser vista em Ferreira et alli., 2013 e 2014), na qual se afirma que a maioria das práticas terapêuticas procura se distinguir das demais práticas extra-científicas a partir de pelo menos dois modos: 1) recorrendo a dispositivos objetivantes, tais como modelos, conceitos e métodos inspirados em outras práticas científicas, e 2) recusando a sugestão e a influência, aspectos que justificariam o sucesso dos dispositivos "à margem da ciência" (Stengers, 1992). Neste aspecto se busca uma distinção entre terapias baseadas em sólidas evidências e as demais terapias que funcionam por "más-razões", o que as caracterizam como "práticas-placebos". Se nas primeiras há a 
expectativa de se produzir representações estáveis de estados internos de sujeitos ou organismos, nas segundas haveria a produção de artefatos (Stengers, 1989). Neste sentido se fez, por exemplo, a distinção operada por Freud entre a psicanálise e as terapias sugestivas.,tomando de empréstimo a diferenciação operada por Leonardo da Vinci entre a per via di porre (pintura) e a per via di levare (escultura): a primeira se realiza a partir do acréscimo de cores na tela, ao passo que a segunda revelaria uma obra escondida na pedra bruta. Para Freud (1969) a psicanálise seguiria o caminho da via di levare ao passo que as terapias sugestivas tomariam o caminho da via di porre. A dispersão das práticas clínicas em geral tem sido analisada por meio de denúncias recíprocas envolvendo a ineficácia, a superficialidade, a sugestão ou a influência.

Porém, a presente pesquisa tem se apoiado na perspectiva de autores da Epistemologia Política (Despret, 2011 e Stengers, 1989, 1992) e da Teoria Ator-Rede (Latour, 1998) propõem outra forma de analisar esta passagem. Estes autores concebem o conhecimento enquanto produção inesperada de efeitos a partir da articulação e co-afetação de entidades heterogêneas, ao invés de supor o conhecimento científico como representação distanciada de objetos a partir de sentenças bem construídas e da purificação de dados. Sem considerar qualquer distinção a priori entre verdade e artifício, a questão da influência não se coloca como problema para os autores supracitados. Sendo o conhecimento considerado como articulação, resta produzir novas formas de diferenciação, entre formas limitadas ou potentes de co-afetação. Nas formas de articulação limitadas, temos dispositivos científicos em que os seres pesquisados são conduzidos ou extorquidos a uma resposta pontual, a uma postura de "docilidade". Por outro lado, temos uma articulação potente quando o testemunho científico não se reduz a condução extorsiva a uma mera resposta; pelo contrário, o dispositivo abre-se à possibilidade de colocação de novos problemas pelos entes pesquisados, configurando deste modo uma relação de recalcitrância. Para os autores citados, é marcante a oposição da 
recalcitrância das entidades não-humanas à docilidade e obediência à autoridade científica dos seres humanos:

Contrário aos não-humanos, humanos tem uma grande tendência, quando colocados em presença de uma autoridade científica, a abandonar qualquer recalcitrância e se comportar como objetos obedientes oferecendo aos investigadores apenas declarações redundantes, confortando então estes investigadores na crença de que eles produzem fatos "científicos" robustos e imitam a grande solidez das ciências naturais (Latour, 2004).

O mesmo autor defende que para as ciências humanas se tornarem científicas, elas precisariam tornar possível a recalcitrância dos seres humanos, ao invés de imitar a objetividade das ciências naturais (Latour, 1997a). Stengers (1989 e 1992) aborda os saberes e práticas psicanalíticos num mesmo registro de análise: assim se por um lado, este saber pôde inventar um novo dispositivo de livre discurso para os sujeitos (Stengers, 1989), ou mesmo um novo tipo de laboratório para produção controlada de transferência (Stengers, 1992), por outro lado, ela se blinda ao risco e à recalcitrância numa fundamentação transcendental ao modo kantiano do conceito de inconsciente (Stengers, 1989) e na colocação assimétrica afora de suas fronteiras do problema da influência (Stengers, 1992). Para a autora, a psicanálise voltaria a se expor ao risco e à recalcitrância se reconsiderasse a relação com aquilo que ela expulsou na demarcação de suas fronteiras científicas, como a hipnose e a influência.

Despret (2004) observa que a possibilidade de recalcitrância se torna ainda mais difícil em dispositivos que envolvem os seus participantes na condição de "ingênuos", que desconhecem o que se encontra em questão nas práticas científicas em que participam. Sujeitos sem a excelência da expertise não trazem risco de tomar posição nas investigações (Despret, 2004, p. 97). É nesse pacto de ingenuidade que os laboratórios psicológicos se fundariam, segundo a autora. Muitos dispositivos clínicos também operariam desta forma, a partir da posição de autoridade do terapeuta e por 
conceitos como o de resistência, que impõe a enunciação de verdade do analista, mesmo sob denegação do analisado; assim, a recusa deste último apenas reforçaria a interpretação do primeiro, reduzindo deste modo a possibilidade do dispositivo clínico se colocar em risco.

Este mecanismo de docilização no campo clínico (graças à autoridade do terapeuta) se reforça na dupla política do segredo enunciada por Despret (2011). Esta operaria primeiro ao transformar em segredo íntimo o que se oferece como produtor de sintomas por parte do paciente, e, segundo, realizando a intervenção terapêutica de modo sigiloso, promovendo assim a proteção de sua competência profissional e dos segredos íntimos dos pacientes. Considerando a origem etimológica da palavra segredo, como particípio passado (secretus) do verbo latino scenere (separar), a autora afirma que as práticas "segredantes" presente nos dispositivos clínicos são tanto "secretantes" quanto "segregantes", pois separam em nossa constituição subjetiva o domínio privado do público. Domínio privado onde se construiriam as verdades íntimas da doença a ser tratada somente pelo segredo operável como sigilo pelos terapeutas.

Um desdobramento desta política do segredo é "o efeito sem nome": o discurso dos pacientes é transformado em autoria anônima no relato de seus casos. Isto se justifica, inicialmente, como um modo de proteger os pacientes, salvaguardando (e certamente produzindo) os seus segredos. Porém, esta proteção também se estende aos terapeutas, salvaguardando-os de problematizações de um domínio público. O contraste entre este anonimato com a autoria em nome dos próprios terapeutas produz uma assimetria nesta produção de conhecimento, semelhante à encontrada nos laboratórios psicológicos que condicionam o sujeito do experimento a um lugar de "sujeito ingênuo". O exemplo clássico seria a pesquisa de obediência à autoridade realizada por Stanley Milgram e analisada por Despret (2004). Em ambos os casos, aos sujeitos envolvidos não caberiam mais do que espaços pré-determinados: ao 
primeiro o das respostas pontuais e ao segundo, o dos sintomas e segredos íntimos. Ambos anônimos em uma produção de conhecimento protagonizada (e por vezes monologada) pelo profissional psi, seja pesquisador ou terapeuta.

Que alternativa seria possível diante da atuação destes "micropoderes" no campo da produção do conhecimento psi? Despret aponta uma possibilidade para os dispositivos psicológicos: estes podem ser "o lugar de exploração e de criação disso que os humanos podem ser capazes quando se os trata com a confiança que se dispensa aos experts" (Despret,2004). Isto favoreceria a produção de uma psicologia que não buscaria mais confirmar o testemunho monocórdio de uma lei universal no segredo ou nas reações dos sujeitos a condições pré-determinadas, mas performaria novas versões nas formas em que podemos nos produzir sujeitos por meio de distintas políticas de pesquisa. Sem qualquer princípio naturalizador prévio que arbitre sobre os assuntos cotidianos e os fundamentos transcendentais da nossa existência. Pois qualquer enunciado só pode se definir na articulação diferencial e múltipla das nossas versões (incluindo as de nossa vida cotidiana).

\section{A positivação da diversidade: entre multiplicidades e pluralidades}

A concepção tanto da Teoria Ator-Rede (doravante TAR) quanto da Epistemologia Política (doravante EP) quanto aos modos de conhecimento entendidos como articulação, onde a recalcitrância seria a forma privilegiada e arriscada, aponta para uma positivação da multiplicidade dos saberes científicos. Quando se fala em multiplicidade, não estão em questão as várias ontologias regionais produzidas pelos diversos modos de conhecimento, tais como reconhecidas pelo racionalismo aplicado de Bachelard e Canguilhem e pelo paradigmatismo de Kuhn. De modo mais específico, todas essas abordagens epistemológicas (incluindo o positivismo) identificam o limiar de cientificidade à unificação de regiões de conhecimento, seja via conceito de projeto e sua racionalidade (racionalismo aplicado), seja por meio da 
noção de paradigma (paradigmatismo). De modo diverso, tanto para a TAR quanto para a EP, a multiplicidade é tomada num sentido ainda mais positivo. Referindo-se especialmente à EP, Latour (2004, p. 220) destaca essa tomada positiva: "a generalização deve ser o veículo para se viajar através do maior número de diferenças possíveis - então maximizando as articulações - e não uma forma de diminuir o número de versões alternativas do mesmo fenômeno". Despret (1999) assim opõe as versões em psicologia, que tomam a diversidade em sentido positivo, das visões que buscam reduzir as diferenças a um modelo identitário. Isso inverte completamente certas críticas ao estatuto científico da psicologia, dada sua pluralidade, como a estabelecida por Canguilhem (1973).

De modo próximo, Mol (2002) e Law (2004) tomam a multiplicidade em um sentido positivo para diversos dispositivos científicos e técnicos a partir de sua concepção de "políticas ontológicas". Para esses autores, mais do que representarem uma realidade pré-dada de diferentes perspectivas, as diversas práticas científicas produzem (toenact) mundos distintos (múltiplos) sem qualquer unidade última (singularidade), mas também não inteiramente desarticulados (pluralidade). É aqui que se faz a especificidade do termo multiplicidade: ela não seria uma anomalia perante um mundo único e singular, tal como conceberia a metafísica euro-americana (Law, 2004, p. 25), nem apontaria uma pluralidade de eventos sem vínculo: "Nós estamos em um mundo em que corpos, ou organizações, ou máquinas são mais que um e menos que muitos. Algo no entre" (Law, 2004, p. 62).

Um exemplo dessa multiplicidade performada pode ser encontrado no estudo de Mol (2002) sobre a arteriosclerose. Esta não seria entendida como um estado patológico inerente ao corpo a ser representado de diferentes perspectivas (no laboratório ou em exames clínicos). Cada uma dessas práticas científicas performa (toenact) um modo de arteriosclerose, uma realidade patológica que não necessariamente se recobre, mas que também não é absolutamente disjunta. Daí o termo "políticas ontológicas", 
pois cada método, cada prática científica, artefaz uma determinada realidade dentre outras possíveis. O que, no jogo com as demais práticas científicas, constitui um multiverso: mais que um e menos que muitos. Retraduzindo a questão proposta pelas epistemologias para uma abordagem CTS com tempero da TAR podemos nos perguntar como as práticas clínicas performam mundos em suas práticas: como multiplicidade ou pluralidade?

\section{Metodologia e estratégias de campo}

Esta discussão conceitual sobre modos de conhecimento como articulação e a positivação de sua diversidade está diretamente articulada aos modos de pesquisa que estão sendo aqui propostos para descrever o campo clínico. Conforme Law (2004), os métodos não são simples dispositivos estáveis de representação de uma realidade pré-dada, mas englobam modos políticos de performação de realidades (o que o autor designa como políticas ontológicas). Neste caso, torna-se importante reportar a uma série de decisões em termos de estratégias de investigação (trabalho já reportado em Ferreira et alli, 2013 e 2014).

Impõe-se, de início, pôr em questão o alcance deste estudo. Ele poderia envolver a análise de um conjunto específico de dispositivos ou técnicas clínicas psi. Contudo, nesta pesquisa, a opção foi por uma entidade ao mesmo tempo mais extensa e mais delimitada do que os diversos dispositivos ligados a uma orientação específica: a Divisão de Psicologia Aplicada (DPA) do Instituto de Psicologia da UFRJ. Mais extensa, pois envolve um campo diverso com práticas clínicas de diferentes abordagens sendo realizadas por estudantes de psicologia em formação, em um serviço oferecido à comunidade, sob a supervisão de coordenadores (professores e técnicos do referido instituto). Neste aspecto, torna-se fundamental tomar em consideração a articulação entre as diversas orientações clínicas, configurando o que Law (2004) delimita como multiplicidade (diversidade articulada) ou pluralidade 
(diversidade inarticulada). Mas por outro lado, esta seria uma entidade mais delimitada, pois ela se circunscreve em um serviço específico e com conexões distribuídas a agentes externos mais delimitados: a grade curricular, os regimentos do Instituto de Psicologia e da UFRJ, a disposição do prédio, além, é claro, das tramas conduzidas por seus pacientes.

Delimitado o campo, quais são seus agentes e como se deu a negociação com o mesmo? A DPA pode ser descrita, em seu segmento humano, pela tríade pacientes estagiários - coordenadores que, no entanto, está vinculado a outros atores: as normativas que regem o funcionamento da DPA, a disposição de seu prédio, a sua relação com o Instituto de Psicologia. A pesquisa inicialmente - nos idos de 2010 entra em contato com este primeiro segmento através de entrevistas com roteiros semiestruturados; tempos depois, em 2014, partindo da constatação de que as supervisões das equipes são um lugar privilegiado de produção e performação da clínica, decide - apostando em uma estratégia etnográfica - que seria interessante acompanhá-las. Como a aposta metodológica dependia da aceitação e colaboração dos respectivos participantes, entramos em contato e agendamos uma conversa com os coordenadores de cada equipe para apresentar a proposta. Com a aprovação, seguimos para a designação dos pares equipe/pesquisador responsável, delimitando os dias de acompanhamento, apresentação da pesquisa ao restante da equipe, assim como a discussão das ferramentas do trabalho de campo e a forma de produzir seus relatos. A pesquisa, portanto, basicamente se faz hoje em dia no acompanhamento em campo destes diversos atores quanto aos seus modos de articulação, constituindo os diversos serviços psi.

Feita o elencamento dos atores, resta dar conta dos modos políticos de articulação com estes atores. Tal acompanhamento seguiria alguns parâmetros já destacados da Teoria Ator-Rede e da Epistemologia Política:

1. Os participantes da pesquisa têm sido tomados como experts no tema, sem 
qualquer divisão prévia entre o saber comum e o saber científico dos pesquisadores (entende-se que os atores pesquisados são os que melhor conhecem suas práticas);

2. Enquanto experts, ou participantes ativos da pesquisa, têm sido demandadas definições sobre suas experiências, práticas, e expectativas quanto ao próprio tratamento, numa posição em que suas abordagens podem redefinir o próprio sentido da investigação (o que previamente foi definido como recalcitrância).

Diante das questões políticas vinculadas ao acompanhamento às atividades terapêuticas no setting terapêutico (dado o lugar do segredo e de proteção), a abordagem tem sido feita por entrevistas abertas aos diversos atores, além do acompanhamento das reuniões de supervisão de orientações diversas. De modo mais preciso o acompanhamento das reuniões de supervisão tem como função propiciar o acesso ao próprio processo em que os relatos dos diversos atores envolvidos na pesquisa são fornecidos, tal como apontam alguns modos de inscrição como a abordagem cartográfica (Kastrup, 2009) e a etnográfica (Caiafa, 2007 e Clifford, 2014). Em ambos, não apenas a processualidade, os jogos de força presentes no ato de pesquisar são descritos, assim como os próprios processos de co-produção e coengendramento entre pesquisadores e pesquisados, focando nos sutis jogos políticos que envolvem a entrada em campo. Visando sustentar a pluralidade das diversas versões em psicologia, estão sendo acompanhadas as reuniões de supervisão de seis estágios de orientações distintas oferecidos na Divisão de Psicologia Aplicada da UFRJ: a) Psicanálise de base Lacaniana; b) Psicanálise de base Winnicottiana; c) Psicanálise Existencial de base Sartreana; d) Terapia Cognitiva-comportamental; e) Análise Institucional Francesa;f) Gestalt-Terapia.

Por outro lado, as entrevistas estão sendo guiadas por alguns roteiros gerais (ver Anexo A), permitindo-se abrir para pistas e indicações dos participantes. Para evitar que as questões ganhassem uma conotação assimétrica e docilizante de testagem de conhecimento, elas têm sido repensadas em seus efeitos de processualidade e de 
produção de mundo (Tedesco, Sade \& Caliman, 2013). Na busca de configurar as posições de expert tem sido pedida a descrição de questões, práticas e experiências vinculadas às práticas terapêuticas, contornando a produção de abstrações e de respostas canônicas. Latour (1997b, p. 28) definiu este problema como produção de uma metalinguagem, em que os participantes apenas forneceriam versões legitimadas de suas práticas. Os roteiros basicamente estariam voltados para:

1. Pacientes em processo terapêutico na DPA/UFRJ;

2. Estagiários dos estágios na DPA/UFRJ;

3. Coordenadores de estágio na DPA/UFRJ;

4. Estagiários responsáveis pela triagem na DPA/UFRJ.

Já foram realizadas 30 entrevistas. Neste processo, os entrevistados têm sido consultados quanto à transcrição de seus relatos, podendo alterá-los ao repensar seu relato. Tal como nós pesquisadores temos oportunidades constantes de fazer. No que concerne à pesquisa etnográfica junto aos grupos de supervisão, é Importante mencionar que a mesma ainda se encontra em curso, tendo atuado e atuando junto a sete diferentes equipes. Mesmo com a pesquisa ainda em curso, já é possível elaborar certas questões colocadas pelo campo pesquisado, permitindo assim que se adiantem apontamentos como os que aqui são apresentados. Especialmente a questão referente à dispersão e articulação dos dispositivos psi, que têm se mostrado um aspecto forte tanto nas entrevistas quanto nas pesquisas etnográficas.

\section{Primeiros sinais do campo: o tempo controverso}

Os artigos anteriores (Ferreira et alli, 2013 e 2014) já puderam destacar as controvérsias em torno das práticas clínicas. O primeiro sinal de controvérsia já despontou na abordagem inicial das equipes. Inicialmente buscávamos diferenciar nas entrevistas pacientes no início de terapia e pacientes experts (Ferreira et alli).. Logo neste primeiro contato com as equipes, mais de uma problematizou o que seriam os 
usuários ou pacientes "estabilizados", com maior tempo de terapia: qual seria o tempo suficiente para podermos observar uma mudança significativa de discurso dos pacientes em relação à terapia? A preocupação com essa questão parece ser um ponto de intersecção entre as diferentes equipes entrevistadas.

$\mathrm{Na}$ equipe de Terapia Cognitiva-Comportamental (TCC), o tempo final de terapia em alguns casos (como terapia de grupo) é dado de antemão. Neste sentido, nosso trabalho seria apenas o de seguir o cronograma da equipe. Esta delimitação, por outro lado), não fez sentido para a equipe de Psicanálise. A eles Ihes parecia um grande absurdo ter que demarcar de antemão um intervalo para estabilização da terapia. Durante a entrevista com esta equipe a questão da necessidade mínima de tempo foi sendo problematizada diversas vezes, e não se chegava a um consenso sobre o que seria um tempo mínimo de estabilização: constantemente nos era perguntado o que significaria tal estabilização.

A discussão com a equipe de Análise Institucional Francesa apresentou outra abordagem da questão do tempo: diante de nossa pergunta sobre o paciente estabilizado, a supervisora nos respondeu com uma discussão filosófica sobre o tempo. Mais especificamente, ela se valeu de uma distinção deleuziana entre Chronos (o tempo contínuo e linear) e Aion (o tempo do acontecimento) para apontar um paradoxo: a "estabilização da terapia" que buscávamos não pertenceria à ordem da linearidade (e sim a Aion), ao mesmo tempo em que o cronograma da pesquisa exigia alguma linearidade (Chronos).

Se para as equipes de Psicanálise e de Análise Institucional Francesa a questão de respeitar a singularidade do tempo se colocava claramente como uma questão ética, sendo teorizada no interior do campo conceitual destas abordagens, no entanto o discurso mais enfático sobre o tempo de terapia foi surpreendentemente de uma estagiária da equipe de TCC. No momento final da entrevista fizemos uma pergunta indicada por Despret (2011), pedindo que o entrevistado se posicione quanto ao que 
seria uma questão capital para uma pesquisa como a nossa. A estagiária assim respondeu:

É uma questão muito prática, as pessoas não têm tempo e dinheiro para ficarem 20 anos em terapia... Eu não acho terapêutico ele estar dependendo de mim para viver... Como é que você lida com o fato de saber que... de repente a tua linha teórica fica um ano, a outra fica vinte...

Por esta entrada inaugurada pela questão do tempo, observamos que entraríamos em território extremamente controverso.

\section{Articulação entre equipes: multiplicidade ou pluralidade}

Uma das expectativas que tínhamos por meio desta pesquisa na DPA era entender se haveria negociação (e como) entre orientações clínicas com parâmetros tão distintos nesse espaço comum. Nos termos de Law (2004), a questão seria saber se neste dispositivo, a DPA, viria se produzir uma configuração múltipla (articulada) ou plural (inarticulada) entre suas diversas práticas psi. A nossa expectativa apontava para a possibilidade de uma radical inarticulação e dificuldade de tradução entre os diferentes projetos psicológicos. Para tal, utilizamos o que Latour (2001, p. 350) designa como "móveis imutáveis", ou seja, a negociação entre técnicas de inscrição de diferentes áreas de pesquisa que "permitem novas translações e articulações, ao mesmo tempo que mantém intactas algumas formas de relação". Diferente de Latour, supusemos que na psicologia, haveria diversos "imóveis mutáveis": imóveis, pois as técnicas de inscrição e práticas na psicologia não circulam entre as diversas versões. E mutáveis pela sua enorme possibilidade de produção de subjetividades por meio de suas práticas.

No caso da DPA a possibilidade de articulação poderia vir de dois fatores: a circulação de pacientes e de estagiários. No primeiro caso valeria acompanhar dois processos: a triagem, processo realizado por todas equipes e a redistribuição de pacientes entre 
equipes. No segundo caso, seria importante observar os contatos entre estagiários, ou a circulação deles entre as equipes. Todos estes modos podem nos apontar para formas de articulação múltiplas ou plurais entre os serviços.

Passemos ao primeiro processo de circulação de pacientes, a triagem: trata-se de um sistema de atendimento pautado na concepção de que todo paciente que se apresente com demanda de atendimento deve ter seus dados coletados, suas reclamações escutadas (pelo prazo máximo de uma hora) e assim produzido, da combinação de ambos, um relato. Este processo é efetuado por qualquer estagiário de plantão e o mesmo fica responsável por encaminhar o documento para a equipe que acredite poder atender melhor o futuro paciente. Contudo, nas entrevistas e no acompanhamento das equipes tem sido observado que a alocação das triagens é feita majoritariamente pela presença de vagas nas equipes (observando limites excludentes, como faixa etária, ou transtorno não atendido) e bem menos pela percepção de que determinada terapia fosse mais indicada para determinado tipo de questão. A escassez de horários e salas disponíveis para atendimento foram os motivos apontados como responsáveis por esta situação. Atualmente o processo de triagem tem sido alvo de muitas críticas entre os estagiários (especialmente em grupos de redes sociais), e constantemente interrompido por impossibilidade de expansão dos atendimentos. Outro fator interessante de ser destacado na observação das relações de triagem é que algumas equipes parecem confiar nas triagens feitas apenas por seus estagiários, tendo em vista aspectos específicos que não seriam abordados da mesma forma pelas demais equipes.

Sobre a circulação de pacientes entre equipes após a triagem, o que podemos colher nas entrevistas com os estagiários e no acompanhamento das equipes foi a descrição plural dos modos de articulação entre as distintas orientações na DPA. Assim, nas perguntas onde o foco central estava voltado para a relação entre as equipes, alguns pontos foram levantados: 
1. Sobre a capacidade das diferentes orientações clínicas, os discursos foram desde uma homogeneização das potencialidades ("todas funcionam bem, o que for bom ao paciente é válido").

2. Quanto ao encaminhamento de um paciente em tratamento com uma equipe para um estágio com outra orientação, apesar de todos terem respondido positivamente a esta possibilidade, casos concretos como estes foram infimamente relatados. E quando feitos, não exemplificavam formas de transição entre clínicas, mas fatores circunstanciais como incompatibilidade de horários entre paciente e estagiário, renovação do quadro na equipe, extinção de equipes, preferências específicas de um paciente, etc. E é interessante observar como estapassagem ocorre entre algumas linhas: Gestalt-Terapia ou Análise Institucional Francesa para Psicanálise Existencial, mas raramente de TCC para Psicanálise ou o revés.

No que diz respeito à conexão entre estagiários, imaginamos inicialmente que a estrutura física da DPA permitisse tal procedimento: uma sala de recepção com computadores e uma vidraça, onde estagiários de todas as equipes se dividem em plantões, em um quadro de horas semanais e sem separação por equipes. Esta configuração particular, com o encaminhamento de pacientes entre abordagens e o espaço da recepção misto, parecia poder criar espaços de trocas entre as equipes, permitindo a circulação de experiências, termos e práticas entre as equipes. No entanto, pelos relatos das entrevistas, constatamos que espaço da recepção é pouco utilizado para trocas teóricas, ou para diálogos entre as equipes como tais (muitos estagiários relataram inclusive o desconhecimento da presença de algumas equipes). Resolvem-se ali questões de natureza burocrática (estratégias de encaminhamento de triagem e compartilhamento de problemas da DPA) e sobre os casos no máximo se compartilha a sua singularidade ou dificuldade. Porém pouco se fala dos modos de atuação e dos conceitos de cada abordagem; somente um estagiário entrevistado definiu a recepção como um espaço de trocas produtivas. 
Contudo, a circulação de estudantes entre orientações distintas é rara. Primeiro, pelas práticas constatadas nas entrevistas e nas observações das equipes. Do lado do estudante, muito da sua educação consiste na constante crítica de outras orientações; quase como se parte da pedagogia de se tornar um psicólogo de uma determinada orientação fosse aceitar sua parcela de críticas contra as outras escolas. Isso está de acordo com a afirmação de Foucault (1994/1957) de que a psicologia cresce pela denúncia dos mitos de outras orientações (sobre a duração e o foco das terapias, bem como os conceitos das orientações). Sobre a difícil articulação entre as abordagens deve ser acrescentado o relato de uma estagiária de uma equipe de psicanálise que participou em sua formação de uma pesquisa com orientação TCCista. Mesmo que distante de qualquer modo de constrangimento mais delicado, a estagiária relatou uma série de pequenos preconceitos cotidianos, como algumas visões estereotipadas sobre ambas abordagens: a TCC como prática de auto-ajuda ou a psicanálise ligada à questão do sexo ou das grandes anormalidades. Relatou inclusive o questionamento de alguns colegas de possuir em seu currículo ambos os trabalhos. Isto leva a concluir que a dificuldade de circulação e composição de um mesmo mundo entre diferentes orientações psi pode chegar ao ponto mais radical de não poder habitar uma mesma carreira profissional ou um mesmo corpo. Sendo necessário quase que um processo de expurgo (das antigas práticas) e de conversão (às novas). A pluralidade é uma questão de corpo.

\section{Conclusão}

Durante boa parte do século $X X$ a discussão sobre a dispersão ou unidade da psicologia balizou o julgamento de sua cientificidade. Trabalhos de boa qualidade descritiva, mas com viés demarcatório (Canguilhem 1973) se sucediam a defesas da unidade dos saberes e práticas psi sem muito lastro conceitual (Lagache 1988/1949). A TAR e a EP no lastro dos Estudos CTS propõe em uma perspectiva simétrica um 
elogio de uma perspectiva não unitária coroada pelos modos recalcitrantes de pesquisar (justamente por sua produção de novas versões). Estas perspectivas animaram novos modos de descrição da dispersão do campo psi, não mais dividido entre unidade versus fragmentação, mas entre multiplicidade versus pluralidade enquanto modos de dispersão articulados ou não.

Este reconhecimento da positividade da dispersão pelos autores da TAR e da EP não garante um reconhecimento da excelência dos saberes e práticas psi. Pois o deslocamento de um juízo dos modos de racionalidade epistemológica para uma avaliação dos modos políticos de articulação nos aponta para outros problemas como a presença dos modos extorsivos na articulação com os testemunhos, a tentativa de supressão das demais versões por algumas que se tomam como visões últimas (na denúncia dos mitos alheios) e a relação de subserviência com modelos ditos objetivantes das ciências naturais.

Quando tomamos a análise do próprio campo clínico em uma de suas versões de dispersão (a DPA da UFRJ) podemos constatar uma pluralidade radical e bélica entre versões que buscam, em alguns momentos, anular as demais, manejando entre a extorsão e o acúmulo de recalcitrância. Neste quadro chegamos a expandir nossa análise desta dispersão plural, propondo um quadro analitico de 12 pontos de análise que descrevem as diferenças entre as práticas clínicas encontradas tanto nas entrevistas quanto no trabalho etnográfico: temporalidades, focos da ação terapêutica, modos pedagógicos, palavras de ordem, vocabulário, autonomia dos estagiários, técnicas de inscrição, etc. Alguns destes 12 pontos de análise foram aqui trabalhados pois estavam vinculados às questões colocadas no início do presente artigo. Já os demais pontos serão aprofundados em artigos futuros por meio de mais indícios oriundos da atividade de campo. Neste ínterim é necessário reconhecer a enorme diversidade (e por que não dizer o pluriverso) dos modos de subjetivação de pacientes, estagiários e supervisores. Com quantas formas clínicas se produz a clínica 
psicológica?

\section{Referências}

Bernard, M. (1983) A psicologia. Em F. Chatelêt (Org.). História da Filosofia. Ideias doutrinas (Vol. 7, pp. 19-88). Lisboa: Dom Quixote.

Caiafa, J. (2007).Aventuras das cidades. Rio de Janeiro: Editora FGV.

Canguilhem, G. (1973). O que é a psicologia. Tempo Brasileiro, 30(31), 104-123

Clifford. J. (2014). A experiência etnográfica. Rio de Janeiro: Editora da UFRJ.

Despret, V. (1999). Cés émotions qui nous fabriquent: etnopsychologie de l'authenticité.[s.I.]: Institut Synthélabo, Le Plessis- Robinson.

Despret, V. (2004). Le cheval qui savait compter.Paris:Les empecheurs de penser en ronde.

Despret, V. (2011). Leitura etnopsicológica do segredo. Fractal: Revista de Psicologia, 23 (1), 5-28. Recuperado de http://periodicos.uff.br/fractal/index

Ferreira, A. L. et alli (2013) A produção de subjetividades em rede: Seguindo as pistas de uma divisão de psicologia aplicada. Universitas Humanística 76, 371-392.

Ferreira, A. L. et alli (2014). Técnicas de si e clínica psi: um campo de estudos etnográficos. Revista Polis e Psique, 4(3), 80-99.

Freud S. (1969). Sobre a psicoterapia. Em S. Freud,Obras completas (Vol. VII). Rio de Janeiro: Imago.

Foucault, M. (1994/1957). La recherche scientifique et la psychologie. Em Defert, D. e Ewald, F. (Orgs.).Dits et Ecrits (pp.165-186). Paris: Gallimard. (Original publicado em 1957)

Kastrup, V. (2009). O método da cartografia e os quatro níveis da pesquisaintervenção. Em L. R. Castro \& V. Besset, (Orgs.). Pesquisa-intervenção na infância e 'juventude'. Rio de Janeiro: Nau.

Lagache, D. (1988/1949). A unidade da psicologia. Tradução de Clara Felgueiras. 
Lisboa: Edições 70 (conferência pronunciada em 1949).

Latour, B. (1997a). Des sujets recalcitrants. Recherche, 301. Recuperado de https://www.larecherche.fr/des-sujets-r\%C3\%A9calcitrants

Latour, B. (1997b). A Vida de Laboratório. Rio de Janeiro: Relume Dumará.

Latour, B. (1998, setembro 13). Universalidade em pedaços. Jornal Folha de São Paulo, Mais!, p.03.

Latour, B. (2001). "Glossário”. Em Latour, B. A esperança de Pandora (pp. 345-356). Bauru: EDUSC.

Latour, B. (2004). How to talk about the body? Body \& Society, 10(2-3), 205-229.

Law, J. (2004). After method: Mess in social science research.[s.I.]: Routledge.

Mol, A. (2002). The body multiple. Durham: Duke University Press.

Pagés, R. (1958) Quelques remarques sur Qu'est-ce que la psychologie? Revue de Métaphysique et de Morale, 63(1), 26-31.

Stengers, I.(1989).Quem tem medo da ciência?. São Paulo: Siciliano.

Stengers,I. (1992). La volonté de faire science. Paris: Synthélabo.

Tedesco, S. H., Sade, C., \& Caliman, L. V.(2013). A entrevista na pesquisa cartográfica: a experiência do dizer. Fractal, Revista de Psicologia, 25(2), 299322.

\section{Declaração do contributo dos autores}

AA, BF, MV, PM, RS contribuíram na escrita e edição da versão final do artigo. Todos os autores contribuíram com o trabalho de campo, elaboração e discussão do texto. 


\section{Formato de citación}

Ferreira, A. A. L., Foureaux, B. F., Pereira, N. B., Lima, R. de S., Brito, D. L., Mendes, P. H.C., Almada, T. R. A., Freire, I. G. \& Santos, M. V. do A. G. (2019). A dispersão da psicologia: do debate epistemológico ao estudo de uma divisão de psicologia aplicada. Psicología, Conocimiento y Sociedad, 9(2), 104-132. doi: http://dx.doi.org/10.26864/PCS.v9.n2.4

ANEXO A: ROTEIROS DE ENTREVISTAS (Os anexos estão presentes igualmente em artigos anteriores da pesquisa: Ferreira et alli, 2013 e 2014).

\section{Para pacientes em terapia nos serviços da DPA/UFRJ:}

1. Vamos supor que você estivesse no nosso lugar de pesquisar sobre a presença da Psicologia na vida das pessoas, tendo como base esse trajeto que vocês percorrem aqui na DPA, o que você acharia interessante perguntar? Como você conduziria a pesquisa? Como você responderia a essa questão? Você teria algum palpite sobre os resultados dessa pesquisa?

2. O que mais te chamou a atenção no ambiente da DPA? Estar neste ambiente afeta alguma coisa em você?

3. Como você descreveria o que acontece no atendimento?

4. Você se prepara de alguma forma para o atendimento? Como?

5. Em algum momento seu terapeuta te explicou o que vocês iriam fazer?

6. Você vê outros meios de lidar com o que te trouxe aqui? Por que você manteve o tratamento psicológico?

7. Existia alguma expectativa de como seria o atendimento? $\mathrm{E}$ agora, você vê diferenças entre o que esperava e o que está acontecendo? 
8. Ao longo das sessões você notou alguma alteração no seu dia a dia? Que mudanças você atribuiria ao atendimento?

9. Que mais você ouviu falar sobre a abordagem psicológica do seu atendimento? Você entrou em contato com outras?

10. Partindo da reflexão que nós fizemos até aqui, como você responderia à pergunta "o que é a psicologia"?

\section{Para estagiários dos serviços da Divisão de Psicologia Aplicada (UFRJ):}

1. Vamos supor que você estivesse no nosso lugar de pesquisar sobre a presença da Psicologia na vida das pessoas, tendo como base esse trajeto que vocês percorrem aqui na DPA, o que você acharia interessante perguntar? como você conduziria a pesquisa? Como você responderia a essa questão? Você teria algum palpite sobre os resultados dessa pesquisa?

2. O que mais te chamou a atenção no ambiente da DPA? Estar neste ambiente afeta alguma coisa em você?

3. Como você descreveria o que acontece no atendimento?

4. Você se prepara de alguma forma para o atendimento? Como?

5. Há diferenças entre sua postura enquanto estagiário da DPA e no seu cotidiano?

Quais diferenças são percebidas? Em que momentos você se dá conta disso?

6. Em algum momento seu supervisor te explicou o que vocês iriam fazer?

7. Que alterações você percebe na vida dos pacientes durante a intervenção do seu grupo de estágio?

8. Como você entende um tratamento bem sucedido?

9. Você encontra dificuldades na integração entre teoria e prática clínica?

10. Como você pensa o alcance da sua abordagem (com o que ela pode ou não lidar)? Você acha que ela serve para a maior parte das demandas presentes aqui na DPA? 
11. O que você acha do processo da triagem e da relação entre as equipes da DPA? 12. Já teve oportunidade ou já encaminhou algum paciente seu para outra linha de tratamento? Se sim, por quê; se não, você encaminharia?

13. Os pacientes falam o que pensam sobre a psicologia e a terapia?

14. Como isso intervém na terapia?

15. Você fazia terapia? (Se sim) Como essa concomitância afeta sua relação com seu terapeuta e seus pacientes?

16. Entre tantas formas de atuação que a psicologia te possibilita, porque a prática clínica te atraiu?

17. Partindo da reflexão que nós fizemos até aqui, como você responderia à pergunta "o que é a psicologia"?

\section{Para coordenadores de estágio da Divisão de Psicologia Aplicada (UFRJ):}

1. Vamos supor que você estivesse no nosso lugar de pesquisar sobre a presença da Psicologia na vida das pessoas, tendo como base esse trajeto que vocês percorrem aqui na DPA, como você conduziria a pesquisa? o que você acharia interessante perguntar? Como você responderia a essa questão? Você teria algum palpite sobre os resultados dessa pesquisa?

2. O que mais te chamou a atenção no ambiente da DPA? Estar neste ambiente muda alguma coisa em você?

3. Como você descreveria o que acontece na supervisão?

4. Você se prepara de alguma forma para na supervisão? Como?

5. Há diferenças entre sua postura enquanto supervisor de estágio na DPA e no seu cotidiano? Quais diferenças são percebidas? Em que momentos você se dá conta disso?

6. Em algum momento você teve que explicar o que vocês iriam fazer? Que orientações você dá, em geral, para um estagiário iniciante? 
7. Que alterações você percebe na vida dos pacientes durante a intervenção do seu grupo de estágio?

8. Como você entende um tratamento bem sucedido?

9. Você encontra dificuldades na integração entre teoria e prática clínica?

10. Como você pensa o alcance da sua abordagem (com o que ela pode ou não lidar)? Você acha que ela serve para a maior parte das demandas presentes aqui na DPA?

11. O que você acha do processo da triagem e da relação entre as equipes da DPA?

12. Sua equipe já teve oportunidade ou já encaminhou algum paciente seu para outra linha de tratamento? Se sim, por quê; se não, você encaminharia?

13. Os estagiários falam o que pensam sobre a psicologia e a terapia?

14. Como isso intervém na supervisão?

15. Você exige ou recomenda que os estagiários façam terapia? Qual diferença você vê em um estagiário que faz terapia? Como você acha que a terapia influencia a formação dos estagiários?

16. Entre tantas formas de atuação que a psicologia te possibilita, porque a prática clínica te atraiu?

17. Partindo da reflexão que nós fizemos até aqui, como você responderia à pergunta "o que é a psicologia"?

\section{Roteiro para pessoal de triagem de estágio da DPA/UFRJ:}

1. Você percebe o direcionamento de determinados casos para determinados tratamentos na triagem?

2. Qual o seu modo de direcionamento dos pacientes que chegam para a triagem?

3. Você proporia de outra forma esse encaminhamento?

4. Como você descreveria o momento do primeiro encontro com o paciente? É necessário esclarecer algo sobre o tratamento? 
5. Vamos supor que você estivesse no nosso lugar de pesquisadores sobre a presença da Psicologia na vida das pessoas, o que você acharia interessante perguntar?

6. Como você responderia a essa questão? 